\title{
Literasi Keuangan Syariah Dikalangan Guru Dan Siswa Sekolah Menengah Kejuruan (SMK) Perpajakan Riau
}

\author{
RENI FARWITAWATI \\ Universitas Lancang Kuning \\ Jln. Yos Sudarso KM 08 Rumbai Telp. (0761) 52581 \\ E-mail : reni@unilak.ac.id
}

\begin{abstract}
At the present time of a new shariah bank keeps growing financial fast paced growth can be in the high number of existing regulations and their financial institutions to retail and corporate banking sources depending on which one financial services based upon that by islamic syariah. Of a new shariah bank financial is expected to be a solutions for the existing regulations and their financial praktik-praktik that would lead to a interest to one of his, masyir and gharar. But the fact that it of a new shariah bank financial up to now is still having a share market wild price swings that low in the state of indonesia as a muslim majority. Of vocational high school Riau and medium micro businesses would which is located on Purnama Street, Pasir Putih had a mentor as many as 32 people and the percentage of students as many as 578 a person. This school having 4 directions in which their four departement: the technique of of computer networks, the administration of office buildings, the banking sector and an accounting. Students and parents to in SMK Taxation Riau and medium micro businesses would comprises a range of ethnicity and religion, religious sect but there are others who non muslims .Most of them come from (the majority of) were muslim. Entire grounds of these reports is presented in his own direction no such as mathematics and science of a new shariah bank about finances, despite the fact that this literasi about finances of a new shariah bank very important considering that murid-murid and teachers in vocational high schools and medium micro businesses would riau predominantly sunni muslim. A method of the implementation of this activity is by means that is socialization talk about finances shariah and discussion about the problems financial partner. The recapitulation result questionnaires among those activities explained that devotion these communities was very beneficial because meningkatkanya understanding teachers and students smk taxation riau about finances syariah.
\end{abstract}

Keywords: Literacy, Financial of Shariah, SMK Taxation Riau

Saat ini keuangan syariah semakin berkembang pesat dengan banyaknya lembaga-lembaga keuangan syariah yang menawarkan jasa keuangan berlandaskan syariat Islam. Keuangan syariah diharapkan dapat menjadi solusi bagi praktik-praktik keuangan yang mengarah pada riba, masyir dan gharar. Tetapi faktanya keuangan syariah hingga saat ini masih memiliki pangsa pasar yang rendah di negara Indonesia yang mayoritas penduduknya muslim.

Islam adalah agama yang sangat memperhatikan literasi. Di dalam Al-Quran juga banyak disebutkan ayat-ayat yang berkaitan dengan kekayaan dan keuangan, seperti zakat, sedekah, wakaf, dan haji yang membutuhkan dana yang cukup besar, sehingga diperlukan perencanaan keuangan. Islam sebagai agama yang mengatur semua aspek kehidupan memberikan arahan dalam hal memperoleh pendapatan atau penghasilan, mengkonsumsinya, menabung, berinvestasi, mengelola harta, dan segala aspek yang berkaitan dengan keuangan (Ahmad Lutfi Abdul Razak dan Rose Abdullah, 2015)

Sekolah Menengah Kejuruan Perpajakan Riau yang berlokasi di Jalan Purnama, Pasir Putih memiliki guru sebanyak 32 orang dan murid sebanyak 578 orang. Sekolah ini memiliki 4 jurusan yaitu Teknik Komputer Jaringan (TKJ), Administrasi Perkantoran, Perbankan dan Akuntansi. Murid dan guru di SMK 
Perpajakan Riau terdiri dari berbagai agama dan suku, ada yang muslim dan ada juga yang non muslim. Sebagian besar dari mereka (mayoritas) adalah muslim. Disemua jurusan tidak ada disajikan mata pelajaran tentang keuangan syariah, padahal literasi tentang keuangan syariah sangat penting mengingat murid-murid dan guru di SMK Perpajakan Riau mayoritas beragama Islam.

Kurangnya pemahaman tentang keuangan syariah dikalangan guru dan murid SMK Perpajakan menyebabkan banyak dari mereka yang masih terjebak dalam masalah riba. Hal tersebut dikarenakan mereka belum memahami konsep dan kebaikan yang diberikan oleh keuangan yang berbasis syariah. Selain itu, masih banyak diantara mereka yang belum mengetahui tentang lembaga-lembaga keuangan syariah yang sudah ada di Pekanbaru. Masih banyak guru dan orangtua murid yang memiliki hutang pada lembaga keuangan konvensional. Jika hal ini dibiarkan terus-menerus akan mengakibatkan rusaknya tatanan akidah bagi umat muslim khususnya dan lemahnya perekonomian bagi masyarakat umumnya

Permasalahannya adalah belum adanya pemahaman tentang keuangan syariah dan kurangnya pengetahuan tentang lembaga keuangan syariah

Target dari program pengabdian kepada masyarakat ini adalah: Guru dan siswa SMK Perpajakan Riau memahami konsep dan kebaikan keuangan syariah. Guru dan siswa SMK Perpajakan Riau mengetahui lembaga-lembaga keuangan syariah yang ada di Indonesia

Luaran yang ingin dicapai dalam kegiatan ini adalah: Mitra menggunakan konsep keuangan syariah dalam kehidupan sehari-hari. Jurnal nasional. Pengayaan bahan ajar/buku ajar.

\section{METODE}

Kegiatan pengabdian kepada masyarakat ini dilakukan di Sekolah Menengah Kejuruan (SMK) Perpajakan Riau. Dalam rangka mencapai tujuan yang tercantum di atas, maka pelaksanaan kegiatan pengabdian masyarakat ini dilaksanakan dengan beberapa metode, yaitu sebagai berikut: Metode Ceramah. Mitra diberikan pengetahuan dan pemahaman tentang konsep keuangan syariah serta lembaga-lembaga keuangan syariah yang telah ada di Indonesia saat ini 1 Metode Diskusi. Mitra diberikan kesempatan untuk mendiskusikan permasalahan yang berkaitan dengan keuangan mitra

Universitas Lancang Kuning merupakan perguruan tinggi yang sudah melakukan kegiatan penelitian dan pengabdian setiap tahunnya. Lembaga yang mengelola kegiatan penelitian dan pengabdian pada masyarakat di Universitas Lancang Kuning adalah Lembaga Penelitian dan Pengabdian kepada Masyarakat atau disingkat LPPM. LPPM Universitas Lancang Kuning merupakan salah satu dari tiga lembaga yang mendapatkan status Madya di Wilayah Kopertis X. Setiap tahun LPPM selalu mengadakan kegiatan penelitian dan pengabdian pada masyarakat dengan sumber dana dari berbagai instansi diantaranya adalah: DIKTI, KOPERTIS WIL X, Universitas Lancang Kuning, Pemerintah Daerah, Departemen terkait dan lain sebagainya. Ini semua diperoleh karena Universitas Lancang Kuning sudah mempunyai banyak tenaga ahli di bidangbidang yang strategis untuk melaksanakan penelitian dan pengabdian kepada masyarakat.

LPPM dalam melaksanakan kegiatan pengabdian pada masyarakat selalu memfasilitasi dosen, memberikan dana, melakukan sosialisasi peraturan baru dan informasi baru. Aktivitas lain yang diadakan oleh LPPM adalah pelatihan penulisan proposal penelitian dan pengabdian, melakukan kegiatan rutin seminar proposal dan seminar hasil kegiatan penelitian dan pengabdian pada masyarakat, dan menginformasikan semua kegiatan yang berhubungan dengan kegiatan penelitian dan pengabdian kepada 
masyarakat. Dalam kaitan fungsi tridarma perguruan tinggi LPPM sebagai lembaga pelaksana kegiatan penelitian dan pengabdian telah melakukan fungsi pengawasan, dimana saat kegiatan yang akan didanai terlebih dahulu dilakukan penandatanganan kontrak dengan dosen yang akan melakukan kegiatan pengabdian. Pada saat kegiatan pengabdian dilaksanakan LPPM, juga melakukan monitoring dan meminta laporan kemajuan kegiatan tiap termen kegiatan yang berjalan. Pada akhir kegiatan LPPM meminta dosen membuat laporan kegiatan sebelum tanggal kontrak berakhir.

Selama ini di Universitas Lancang Kuning setiap tahun selalu ada dana pengabdian yang bersumber dari dana Dipa Universitas setiap semester dan selalu ada dana dari DIKTI yang diperoleh, ini artinya Universitas Lancang Kuning sudah layak untuk mengelola pengabdian kepada masyarakat dalam pelaksanaan Tridarma Perguruan Tinggi

Tim PKM ini berasal dari Fakultas Ekonomi Universitas Lancang Kuning yang memiliki latar ilmu yang berbeda. Semua anggota tim telah memiliki pengalaman dalam kegiatan pengabdian masyarakat yang terdiri dari: Reni Farwitawati, sebagai ketua tim memiliki latar belakang akuntansi khususnya akuntansi sektor publik dan studi kelayakan bisnis. Berpengalaman dalam berbagai kegiatan penelitian dan PKM yang dibiayai oleh DIKTI dan LPPM Universitas Lancang Kuning seperti memperoleh dana penelitian dosen pemula sebanyak 4 kali yaitu pada tahun 2014 dengan judul Pengaruh Ketidakpastian Lingkungan Terhadap Karakteristik Sistem Informasi Akuntansi Manajemen Pada Bank Syariah Mandiri Pekanbaru. Tahun 2014 dengan judul penelitian Pengaruh Atribut Kualitas Audit Terhadap Kepuasan Klien (Studi Kasus BUMD di Kota Pekanbaru), tahun 2015 dengan judul penelitian Anggaran Sebagai Alat Perencanaan Dan Pengendalian Studi Kasus Pada Badan Perencanaan Pembangunan Daerah (BAPPEDA) Provinsi Riau dan pada tahun 2016 dengan judul penelitian Pengaruh Partisipasi Anggaran, Keadilan Distributif, Dan Komitmen Organisasi Terhadap Kecenderungan Penciptaan Senjangan Anggaran. Untuk PKM pernah memperoleh dana dari LPPM sebanyak 3 kali yaitu pada tahun 2013 dengan judul Perencanaan Strategis Pengembangan Usaha Sektor UMKM sebagai Upaya Percepatan Kelurahan Sei Mempura Kabupaten Siak Sri Indrapura Propinsi Riau sebagai Kawasan Ekowisata. Pada tahun 2015 dengan judul Pengembangan Usaha Produk Jajanan Dalam Upaya Meningkatkan Ekonomi Keluarga di Sei Mempura Kabupaten Siak Propinsi Riau. Dan pada tahun 2017 dengan judul Pengelolaan Keuangan Bagi Usaha Mikro Kecil Menengah (UMKM) Dikelurahan Simpang Baru Kecamatan Tampan Pekanbaru. Souvya Fithrie, sebagai ketua tim memiliki latar belakang manajemen khususnya manajemen sumber daya manusia. Berpengalaman dalam berbagai kegiatan penelitian dan PKM yang dibiayai oleh DIKTI dan LPPM Universitas Lancang Kuning seperti memperoleh dana penelitian dosen pemula sebanyak 1 kali yaitu pada tahun 2017 dengan judul Pengaruh Resiko, Manfaat dan Kemudahan Penggunaan Terhadap Kepercayaan Nasabah Dalam Menggunakan Internet Banking Di Pekanbaru (Studi Kasus Pada Nasabah Bank Mandiri), Untuk PKM pernah memperoleh dana dari LPPM sebanyak 2 kali yaitu pada tahun 2010 dengan judul Kiat-Kiat Membangun Usaha Kecil (home industry). Pada tahun 2011 dengan judul Pengolahan Ubi Kayu Menjadi Tepung Mocaf Untuk Menambah Pendapatan Keluarga. Masirun, sebagai anggota tim memiliki latar belakang manajemen khususnya kewirausahaan. Berpengalaman dalam berbagai kegiatan penelitian dan PKM yang dibiayai oleh DIKTI dan LPPM Universitas Lancang Kuning.

\section{HASIL}

Kegiatan literasi keuangan syariah di kalangan guru dan siswa Sekolah 
Menengah Kejuruan (SMK) Perpajakan Riau, dilakukan di salah satu kelas SMK Perpajakan Riau. Pelaksanaan kegiatan ini terlaksana setelah dilakukan beberapa kali koordinasi dengan pihak SMK Perpajakan Riau tentang materi dan peserta pengabdian kepada masyarakat di SMK Perpajakan Riau yang menjadi target PKM, waktu pelaksanaan PKM serta tempat yang layak sebagaimana tertuang dalam dokumen rencana kegiatan.

Pelaksanaan PKM pada tanggal 14 Januari 2019. Pada jam 10.30 sampai dengan 12.00. Acara pertama diawali dengan kata sambutan dari Kepala Sekolah SMK Perpajakan Riau. Selanjutnya, dilanjutkan dengan memberikan literasi kepada peserta tentang hal-hal yang berkaitan dengan keuangan syariah.

Evaluasi pada tahap pertama sesuai dengan indikator dan rancangan evaluasi diperoleh data sebagai berikut: Jumlah peserta yang hadir sebanyak 25 orang dari 30 peserta yang diharapkan hadir sehingga lebih dari target kegiatan. Keantusiasan peserta sangat terlihat jelas dimana hampir seluruh peserta aktif terlibat dalam proses kegiatan hingga selesai. Evaluasi pada tingkat kesukaan konsumen (peserta) hampir semua peserta $>95 \%$ menyatakan suka dengan hasil kegiatan.

\section{PEMBAHASAN}

Penyampaian materi oleh tim PKM dilakukan dengan sistem diskusi. Setelah seluruh materi disampaikan, dilanjutkan dengan diskusi terbuka dan berbagi pengalaman dengan para peserta. Penyampaian materi dilakukan dengan bahasa yang mudah dipahami. Untuk kelancaran, kenyamanan dan ketertiban penyelenggaraan kegiatan maupun diskusi yang berlangsung, maka strategi yang dilakukan adalah dengan melakukan dialog interaktif pada setiap materi yang disampaikan.

Tahap pengamatan secara mendalam dan komprehensif (monitoring) dan evaluasi pelaksanaan kegiatan literasi terhadap para peserta merupakan tolok ukur untuk mengetahui capaian atau terdapatnya peningkatan pengetahuan, pemahaman dan perilaku (kompetensi) peserta.

Kegiatan monitoring partisipasi peserta dilihat sejak dimulainya sosialisasi pelatihan sampai pada penutupan pelatihan. Dalam tahap ini, setiap materi yang disampaikan oleh tim PKM mendapat respon aktif dari seluruh peserta dengan perhatian yang optimal. Begitu pula pada alokasi waktu untuk diskusi, keaktifan para peserta juga dimonitoring, yang mana sebagian besar peserta sangat aktif mengajukan pertanyaan bahkan berulangulang sesuai dengan masalah yang dihadapinya, dan cukup relevan dengan materi yang disampaikan atau masih terkait dengan keuangan syariah. Berbagai pertanyaan yang diajukan peserta, narasumber berupaya memberikan jawaban dengan memberikan contoh dalam mengatasi setiap masalah yang sudah dialami dan sedang dihadapi dengan menggunakan bahasa yang mudah dipahami oleh peserta.

Sebagian besar dari peserta sangat tertarik mengajukan pertanyaan seputar pemhaman tentang keuangan syariah. Selanjutnya, penyelenggaraan kegiatan PKM dievaluasi oleh peserta atas kinerja prosesi pelaksanaan kegiatan ini. Hasil yang diperoleh dari penyebaran kuesioner ke peserta kegiatan sebanyak 25 orang, sebelum dan sesudah kegiatan dilaksanakan adalah mayoritas peserta belum mengetahui banyak tentang keuangan syariah, terlebih lagi siswa. Hal ini terlihat dari jawaban peserta pada pertanyaan no 1-6 pada kuesioner. Secara keseluruhan pelaksanaan PKM cukup berhasil karena peserta mampu menguasai materi, baik tentang keuangan syariah maupun perbankan syariah. Peserta juga menjadi lebih mengerti manfaat dari keuangan syariah. Hal ini terlihat dalam jawaban peserta pada pertanyaan no 1-6 pada kuesioner sesudah kegiatan PKM diberikan. 
Tabel 1: Tingkat Pengetahuan Peserta Sebelum dan Sesudah Pelaksanaan PKM

\begin{tabular}{|c|c|c|c|c|c|c|c|}
\hline \multirow{2}{*}{ No } & \multirow{2}{*}{ Pernyataan } & \multicolumn{3}{|c|}{ Sebelum } & \multicolumn{3}{|c|}{ Sesudah } \\
\hline & & $\mathrm{Ya}$ & Tdk & $\%$ & Ya & Tdk & $\%$ \\
\hline 1 & $\begin{array}{l}\text { Apakah saudara } \\
\text { sudah mengetahui } \\
\text { mengetahui } \\
\text { tentang keuangan } \\
\text { syariah }\end{array}$ & 1 & 24 & 4 & 25 & 0 & 100 \\
\hline 2 & $\begin{array}{l}\text { Apakah saudara } \\
\text { sudah memahami } \\
\text { apa itu riba }\end{array}$ & 2 & 22 & 8 & 25 & 0 & 100 \\
\hline 3 & $\begin{array}{l}\text { Apakah saudara } \\
\text { mengetahui } \\
\text { produk-produk } \\
\text { perbankan syariah }\end{array}$ & 0 & 25 & 0 & 25 & 0 & 100 \\
\hline 4 & $\begin{array}{l}\text { Apakah saudara } \\
\text { mengerti } \\
\text { perbedaan } \\
\text { keuangan syariah } \\
\text { dengan keuangan } \\
\text { konvensional } \\
\end{array}$ & 0 & 25 & 0 & 25 & 0 & 100 \\
\hline 5 & $\begin{array}{l}\text { Apakah saudara } \\
\text { mengetahui } \\
\text { kelebihan } \\
\text { keuangan syariah }\end{array}$ & 0 & 25 & 0 & 25 & 0 & 100 \\
\hline 6 & $\begin{array}{l}\text { Apakah saudara } \\
\text { mengetahui } \\
\text { manfaat keuangan } \\
\text { syariah }\end{array}$ & 1 & 24 & 4 & 25 & 0 & 100 \\
\hline 7 & $\begin{array}{l}\text { Kegiatan } \\
\text { sosialisasi ini } \\
\text { sangat bermanfaat } \\
\text { untuk membantu } \\
\text { peningkatan } \\
\text { perekonomian } \\
\text { masyarakat }\end{array}$ & 20 & 5 & 80 & 25 & 0 & 100 \\
\hline 8 & $\begin{array}{l}\text { Penyampaian } \\
\text { materi oleh } \\
\text { narasumber sangat } \\
\text { bagus }\end{array}$ & 10 & 15 & 40 & 25 & 0 & 100 \\
\hline 9 & $\begin{array}{l}\text { Waktu diskusi } \\
\text { untuk } \\
\text { penyampaian } \\
\text { masalah-masalah } \\
\text { yang dihadapi } \\
\text { peserta dalam } \\
\text { memahami } \\
\text { keuangan syariah } \\
\text { cukup memadai }\end{array}$ & 25 & 0 & 100 & 25 & 0 & 100 \\
\hline 10 & $\begin{array}{l}\text { Perlu adanya } \\
\text { edukasi yang lebih } \\
\text { intensif untuk } \\
\text { meningkatkan } \\
\text { pengetahuan dan } \\
\text { informasi yang } \\
\text { lebih optimal } \\
\text { mengenai } \\
\text { keuangan syariah }\end{array}$ & 9 & 16 & 36 & 25 & 0 & 100 \\
\hline
\end{tabular}

Sumber: Hasil Olah Data Kuesioner

Berdasarkan tabel diatas terlihat bahwa mayoritas peserta belum mengetahui banyak tentang keuangan syariah, terlebih lagi siswa. Hal ini terlihat dari jawaban peserta pada pertanyaan no 1-6 pada kuesioner. Secara keseluruhan pelaksanaan
PKM cukup berhasil karena peserta mampu menguasai materi, baik tentang keuangan syariah maupun perbankan syariah. Peserta juga menjadi lebih mengerti manfaat dari keuangan syariah. Hal ini terlihat dalam jawaban peserta pada pertanyaan no 1-6 pada kuesioner sesudah kegiatan PKM diberikan.

Dengan diadakan literasi keuangan syariah ini semua pihak memperoleh hasil dan manfaat, terutama bagi guru dan siswa SMK Perpajakan Riau. Tim PKM mampu memberikan pengetahuan untuk masyarakat tentang keuangan syariah. Terjalin kerjasama antara pihak SMK Perpajakan Riau dan dosen pelaksana program pengabdian kepada masyarakat khususnya dan Universitas Lancang Kuning pada umumnya. Dosen mampu melaksanakan tri dharma perguruan tinggi yaitu pengabdian kepada masyarakat dengan terlaksananya kegiatan ini.

\section{SIMPULAN}

Hasil dari diselenggarakan nya literasi keuangan syariah di kalangan guru dan siswa Sekolah Menengah Kejuruan (SMK) Perpajakan Riau ini adalah: Meningkatkanya pemahaman guru dan siswa SMK Perpajakan Riau tentang keuangan syariah. Meningkatkan pengetahuan guru dan siswa SMK Perpajakan Riau tentang produk-produk perbankan syariah.

Kegiatan serupa dapat dilaksanakan kembali di sekolah-sekolah lainnya dengan peserta yang lebih banyak lagi.

\section{DAFTAR RUJUKAN}

Abdullah Rose dan Razak Abdul Haji Lutfi Ahmad. 2015. Exploratory Research Into Islamic Financial Literacy in Brunei Darussalam. https://www.researchgate.net/publi cation/283225608. Diunduh pada tanggal 30 Oktober 2018

Diana Djuwita dam Ayus Ahmad Yusuf. 2018. Tingkat Literasi Keuangan 
Syariah Dikalangan UMKM dan Dampaknya Terhadap Perkembangan Usaha. Jurnal AlAmwal Vol. 10 No. 1 Tahun 2018

Salmah Said dan Andi Muhammad Ali Amirudin. 2017. Literasi Keuangan Syariah di Perguruan Tinggi Keagamaan Islam (Studi Kasus UIN Alauddin Makasar). Jurnal Al-Ulum Vol. 17 No. 1 Juni 2015

https://republika.co.id/berita/ekonomi/syariah -ekonomi/17/10/27/oyh59r382-ojkakui-inklusi-dan-literasi-keuangansyariah-masih-minim. Diakses tanggal 30 Oktober 2018

http://parstoday.com/id/news/indonesiai53894literasi_keuangan_syariah_di indonesia. Diakses tanggal 30 Oktober 2018

http://www.tribunnews.com/regional/2018/0 2/19/pentingnya-pemahamanliterasi-keuangan-syariah. Diakses tanggal 30 Oktober 2018 